- Maria Célia B. F. de Melo

- Rosane do R. Charello

\section{Intubação traqueal em paciente acometido de espondilite anquilosante}

\author{
Instituto de Neurologia de Curitiba, Hospital Ecoville, Curitiba, Paraná
}

INTRロDUÇÃ̃

A espondilite anquilosante (EA) é um processo inflamatório que causa diminuição da mobilidade da coluna vertebral. A extrema deformidade da coluna vertebral, em especial no pescoço, pode tornar muito difícil a intubação da traquéia e a ventilação do paciente.

RELATD DO CASD

Paciente do sexo masculino, 47 anos, IHCC 32, P2 (antigo ASA II), Goldman I, consciente, orientado. Dados vitais: pressão arterial 108/75 mmHg, freqüência cardíaca em 76 bpm, freqüência respiratória de $18 \mathrm{ipm}$, temperatura de $36,5^{\circ} \mathrm{C}$. Apresenta comprometimento ósseo importante de quadril, "coluna em bambu" com fraturas nos níveis da décima primeira e décima segunda vértebras torácicas, anquilose em quinta vértebra lombar e primeira sacral. Avaliação de vias aéreas: fixação cervical em flexão, pescoço curto, boca pequena com abertura menor de $3 \mathrm{~cm}$, próteses dentárias fixas em incisivos superiores, teste de Mallampati Classe II, distância tireomentoniana menor de $6 \mathrm{~cm}$. Tabagista. Exames complementares hematológicos dentro da normalidade. Eletrocardiograma apresentando ritmo sinusal com distúrbio da condução do ramo direito e alteração da repolarização ventricular. Ecocardiograma com diminuição do relaxamento de ventrículo esquerdo. Foi explicado ao paciente na visita pré-operatória os eventos que ocorreriam, incluindo a realização de intubação nasotraqueal com ele consciente. $\mathrm{Na}$ sala de operaçôes, o paciente foi posicionado e mantido o mais confortável possível com o auxílio de coxins. Procedeu-se a monitorização não-invasiva e a pré-oxigenação por meio de máscara facial. Foi instalado um cateter de teflon $16 \mathrm{G}$ em acesso venoso periférico e iniciada a infusão contínua (com auxílio de bomba infusora Baxter) de remifentanil de $0,1 \mathrm{mcg} / \mathrm{kg} / \mathrm{min}$. Foi obtida a anestesia tópica borrifando-se lidocaína $10 \%$ na língua, orofaringe e faringe, e utilizando-se lidocaína gel 2\% nas fossas nasais. Após 10 minutos, iniciaram-se as manobras de compressão laríngea externa, a introdução do tubo traqueal de polivinil Portex 8,5 , previamente amolecido ao ter sido mergulhado em cuba-rim com soro fisiológico aquecido, direcionado por guia Macintosh-Venn-Escchmann em narina esquerda. Na primeira tentativa, foi percebido ruído respiratório no tubo e o guia foi retirado; foi dada continuidade à anestesia geral balanceada. A estabilidade cardiovascular foi mantida durante todo o procedimento. Após o término da artroplastia de quadril, realizada com sucesso, o paciente foi extubado, encaminhado à sala de recuperação estável e, posterirmente, ao leito hospitalar, confortável e sem dor.

DISCUSSÃ́

Em pacientes acometidos de EA, pode ocorrer a impossibilidade de intubação, e mesmo da ventilaçáo, em virtude da fusão ou deformidade da coluna cervical. Fraturas da coluna podem acontecer durante a manipulação da via aérea. Muitos pacientes podem ter alteraçôes no sistema cardiovascular, como cardiomiopatias e defeitos da condução, facilitando a presença de arritmias. No presente caso, o bom resultado deveu-se fundamentalmente ao preparo prévio adequado do paciente, ao conforto e à analgesia. $\mathrm{O}$ uso da técnica correta e do material apropriado e a disponibilidade de outros instrumentos, como máscara laríngea, laringoscópio Bullard e material para cricotireoidostomia, facilitaram e permitiram tranqüilidade na realização da intubação nasal às cegas.

REFERENCIAS

. Roizen MF, Fleisher LA. Essence of anesthesia practice. 1st ed. Philadelphia: WB Saunders 1997.p.144.

2. Pao-Ping L, et al. The intubating mask airway in severe ankylosing spondylitis. Can J Anesth. 2001;48:1015-19.

3. Melhado V, Fortuna. Via aérea difícil. In: Curso de educação à distância. IV. SBA. São Paulo. Office, 2004.

Endereço para correspondência:

Rosane do R. Charello

Rua Jeremias Maciel Perreto, 300 - Campo Comprido

Curitiba (PR) - CEP 81210-310 